\title{
Policymaker perceptions of citizen needs: heuristics, accuracy, and partisan differences
}

\author{
DANIEL E. BERGAN * \\ Department of Communication \& James Madison College, Michigan State University, East Lansing, MI, USA \\ NATALIE FITZPATRICK \\ Center for Local, State, and Urban Policy (CLOSUP), University of Michigan Gerald R. Ford School of Public \\ Policy, Ann Arbor, MI, USA
}

\begin{abstract}
Do policymaker perceptions reflect actual citizen needs? A vast literature has explored the extent to which policy is responsive to public opinion, but there is little systematic work on policymaker perceptions of social problems. We quantify social problems with a unique dataset of the number of phone calls placed by citizens to a free service that connects Michigan residents to service providers. We combine these data with a survey of local policymakers' perceptions of social problems facing their own city shows, consistent with theories of bounded rationality, that policymakers use heuristics to make judgments about the extent of constituent needs in their city, and that policymaker perceptions reflect the prevalence of needs. However, partisan perceptions of needs diverge, with Democrats consistently perceiving greater needs than Republicans. There is no evidence that policy activity on the needs in the sample is responsive to constituent needs. We conclude with implications for theories of policy making and avenues for future research.
\end{abstract}

Submitted 18 May 2020; revised 3 November 2020; accepted 6 November 2020

\section{Introduction}

In early 2020, California Governor Gavin Newsom addressed the growing homelessness crisis in the state. 'The hard truth is for too long we've ignored this problem,' the Governor said of the $16 \%$ increase in homelessness in

\footnotetext{
* Correspondence to: Department of Communication \& James Madison College, 479 Communication Arts Building, Michigan State University, East Lansing, MI 48824, USA. E-mail: bergan@msu.edu
} 
2019. The Governor expended considerable political capital in directing attention to housing needs, devoting the entire state of the state address to implore legislators to support an ambitious agenda to address homelessness (Fuller, 2020).

The California homelessness example involved a sudden dramatic increase in policymaker attention to a worsening problem. One possible explanation for the sudden increase in attention is that policymakers rely on indirect sources of information when evaluating a problem. Although these indirect sources may serve as an easy-to-use, efficient source of information about a problem in most circumstances, on rare occasions when indicators that policymakers rely on are not valid, they may misjudge the seriousness of a problem. Considering the California homelessness example, for the most part, economic growth corresponds with improvements in a variety of citizen needs, including housing. Policymakers are safe in assuming that with economic growth, homelessness, and other problems would become less urgent. The situation in California, however, violated this pattern: homelessness increased dramatically across multiple California cities, whereas the state enjoyed economic growth far above the national average for multiple years.

Governor Newsom's address and ambitious policy agenda after a dramatically worsening problem should be familiar to policy scholars as an example of dramatic policy change after a long period of inaction (Kingdon, 1984; Jones $\&$ Baumgartner, 2005); but, what are the micro-level processes that underly this pattern? How accurate are policymakers' perceptions of problems? Major theories of policy making claim that policymakers are influenced by indicators of problems (Kingdon, 1984; Jones \& Baumgartner, 2005), but what are these indicators, and how are they used?

The answers to these questions are unclear as there is little empirical work on policymaker perceptions of problems. This is in contrast to the vast literature exploring the extent to which policy is congruent with and responsive to public opinion (Manza \& Cook, 2002; Burstein, 2003; Shapiro, 2011): there is no comparable body of systematic work on policymaker perceptions with respect to social problems. Jones and Baumgartner (2004), for example, explore the relationship between policymaker attention to issues and priorities of the public, but the latter is distinct from objective indicators of actual needs.

Policymaker perceptions of citizen needs are important for a number of reasons. First, policymaker attention to problems is a critical component of many influential theories of policy making. For example, the Multiple Streams Approach proposes that policy change occurs when evidence of problems combines with policy solutions in a favorable political environment (Kingdon, 1984; Zahariadis, 2003). In theoretical approaches such as agenda setting (Dearing \& Rogers, 1996) and Punctuated Equilibrium 
Theory (Baumgartner \& Jones, 1993), attention to problems is also a critical predictor of policy change.

Second, the empirical literature on policy responsiveness relates to one normative conceptualization of representation, evaluating the extent to which policymakers respond to public opinion. However, another normative conceptualization is the trustee model of representation, in which a policymaker is entrusted to use his or her judgment to address citizen needs and solve social problems (Pitkin, 1967; Mansbridge, 2003; Rehfeld, 2009). Put (perhaps too) simply, the focus of empirical literature on representation has been on what citizens want rather than what they need. Policymaker perceptions of problems constitute one important component of this trustee model of representation.

The current analysis quantifies social problems with a unique dataset of the number of phone calls placed by citizens to a free service that connects Michigan residents to service providers. The calls are coded into a set of categories of constituent needs, including emergency housing, public transportation, and food, among others. The data on needs in Michigan cities are combined with a survey of the state's local policymakers, which includes a battery of items about policymakers' perceptions of social problems facing their own communities.

The combination of objective evidence of citizen needs and survey data produces a number of important findings. The analysis shows, in line with major theories of policy making, that policymakers use heuristics to make judgments about the extent of constituent needs in their city, and that policymaker perceptions are responsive to the magnitude of the problem in their city. Although using heuristics enables policy perceptions to track citizen needs, the heuristic approach leaves considerable uncertainty concerning citizen needs. One consequence of this uncertainty is that partisan perceptions of needs diverge, with Democrats consistently perceiving greater needs than Republicans. Also, although policymaker perceptions covary with actual needs, there is no evidence of responsiveness in actual policy outcomes, suggesting that features of the policy process beyond individual policymaker perceptions impede responsiveness.

\section{Literature review}

Misperceiving problems that affect their constituents may have serious electoral consequences for policymakers if left unaddressed. However, policymakers do not have direct access to information about problems affecting their constituents (Elmendorf \& Wood, 2018), instead relying on indirect sources of information about citizen needs, including colleagues, interest 
groups (Wright, 1996), and contacts with constituents (Bergan, 2009; Bergan \& Cole, 2015). Although at the local level, policymakers have fewer resources than state and federal policymakers, including staff, access to group representatives, and other resources, local policymakers generally have the advantage of representing smaller, more homogeneous communities, simplifying the task of forming accurate perceptions of the prevalence of problems.

Major theories of policy making, including the Multiple Streams Approach (Kingdon, 1984; Zahariadis, 2003) and Punctuated Equilibrium Theory (Baumgartner \& Jones, 1993), propose that policy making is characterized by bounded rationality. Simon (1957) proposed the 'principle of bounded rationality' that ' $[t]$ he capacity of the human mind for formulating and solving complex problems is very small compared with the size of the problems whose solution is required for objectively rational behavior in the real world rationality' (p. 198). This principle about the size of problems is in line with policymaking theories emphasizing the complexity of the policy context (Kingdon, 1984; Baumgartner \& Jones, 1993; Zahariadis, 2003).

Theories of bounded rationality propose that decision makers cope with complexity by applying heuristics to make judgments. A heuristic is 'a strategy that ignores part of the information, with the goal of making decisions more quickly, frugally, and/or accurately than more complex models' (Gigerenzer \& Gaissmaier, 2011, p. 454). Although Gigerenzer and Gaissmaier's (2011) definition proposes accuracy as one of the goals of heuristic use (discussed in greater detail below), there is a debate as to what extent heuristics lead to accurate perceptions (Bendor, 2003). For example, policymakers may rely on the availability heuristic (Tversky \& Kahneman, 1973) using evidence that is easy to call to mind to make judgments, such as using communications from constituents to make judgments about public opinion (Miler, 2007; Bergan, 2009; Bergan \& Cole, 2015). An extremely influential line of work in psychology proposes that heuristic use can lead to a host of biases and errors in judgments (Kahneman et al., 1982), and recent work suggests specifically that policymakers are not immune to a number of these biases (Sheffer, 2018). For example, constituents who contact policymakers about problems compose a biased sample of constituents, as policymakers are more likely to hear from constituents who are mobilized to contact them (Broockman \& Skovron, 2018) and from those who have higher socioeconomic status (Bergan \& Cole, 2015). Drawing judgments from available information, including contacts from constituents, could lead to biases in judgments about needs, as people with serious needs may be under-represented among constituents who contact their representatives, leading policymakers to underestimate the extent of a social problem. In addition, policymakers from the major parties may be differentially exposed to people with specific needs, leading to 
differences in perceptions among policymakers from the major parties (Broockman \& Skovron, 2018).

Although heuristics have been associated with biases in judgments, construed as a second-best approach to optimization, Gerd Gigerenzer and colleagues (Gigerenzer, 2008; Brighton \& Gigerenzer, 2011; Gigerenzer \& Gaissmaier, 2011) argue that these conclusions ignore the role of the decision-making environment in bounded rationality. Simon (1990), for example, argues that '[h]uman rational behavior... is shaped by a scissors whose two blades are the structure of task environments and the computational capabilities of the actor' (p. 7).

Policymakers may rely on a key feature of the community, such as socioeconomic status, to form perceptions of the prevalence of needs. This approach to decision making - using a single valid cue to making a decision - belongs to a class that Gigerenzer and Gaissmaier (2011) refer to as 'one-reason decision making,' and there is evidence that it is used by experts in other contexts (Garcia-Retamero \& Dhami, 2009). ${ }^{1}$ Using one valid piece of information leads to relatively accurate judgments compared with other methods when uncertainty is high (Hogarth \& Karelaia, 2007; Gigerenzer \& Gaissmaier, 2011) and when cues are redundant (Dieckmann \& Rieskamp, 2007; Gigerenzer \& Gaissmaier, 2011), features that characterize decision making in policy making (Kingdon, 1984; Baumgartner \& Jones, 1993; Zahariadis, 2003, 2008, 2013; Ackrill et al., 2013). Rather than being able to draw from an encyclopedic store of knowledge about needs in their community and applying a complex weighting scheme to this information to make judgments about problems, policymakers may instead use simple, indirect cues to make judgments about needs.

Even if heuristics lead to roughly accurate judgments, the ambiguity of the decision environment may leave some room for policymakers' own biases to color their perceptions. Policymakers' perceptions could be influenced by directional goals (Kunda, 1990; Carpenter, 2019) leading them to selectively draw on evidence to arrive at conclusions about the world that fit with their partisan predispositions (Leeper \& Slothuus, 2014). Democrats and Republicans have different attitudes about the role of government in addressing social needs, which could lead to consistent differences in perceptions of the prevalence of needs in the public. Motivated reasoning is particularly likely under conditions with some ambiguity (Kunda, 1990; Carpenter, 2019). Moreover, the relevance of directional goals has increased in recent

1 This approach is similar to Brunswik's (1952) 'lens model' which has been applied to interpersonal judgments (Gosling et al., 2002) and risk perceptions (Schmälzle et al., 2019). 
years with ideological polarization among elected officials (Poole \& Rosenthal, 1997). Although policymakers have a strong electoral incentive to form accurate perceptions of problems faced by groups in their jurisdictions, this incentive depends on the political power, visibility, and public image of the group in question (Schneider \& Ingram, 1993). In addition, the political alignment of the affected groups may provide different incentives for members of each major party to pay attention to group needs (Butler \& Broockman, 2011), another reason to expect divergence in perceptions between the two major parties.

Policymakers have an electoral incentive to form accurate perceptions of constituent needs. Policymakers who have won elections presumably are selected in part based on their familiarity with the jurisdiction, and serving in office provides opportunities to learn more about the jurisdiction from colleagues and communications from constituents and organized groups (Fenno, 1978). However, policymakers in a complex environment do not have direct access to the scope of citizen needs, instead relying on heuristics to make judgments. Heuristics may, for the most part, serve policymakers well in forming judgments about citizen needs, although the inherent ambiguity in the environment, the influence of motivated reasoning, and differing incentives may limit the responsiveness of perceptions and contribute to diverging perceptions between policymakers from the two major parties.

\section{Method}

The current study combines a statewide survey of local public policymakers in Michigan, including items about perceptions of constituent needs, with objective data of constituent needs and the number of calls placed to a statewide service on a number of different constituent needs. The current section describes the dataset of calls and the survey of local policymakers.

Michigan 2-1-1 is a free, confidential service that connects residents with service providers, managed by the Michigan Association of United Ways (https://www.uwmich.org/mi2-1-1). The Michigan Association of United Ways provided data on the number of calls placed in calendar year 2017 for all cities in Michigan. The calls were coded by the Michigan Association of United Ways into a number of needs categories, including housing, food/ meals, transportation, health care, individual, family and community support, employment, and mental healthladdictions. As multiple needs might be expressed in a single call, the current data code each distinct topic need separately. For example, if a caller had three separate requests (two for housing and one for employment), this would be coded as two distinct needs 
(housing and employment). ${ }^{2}$ The natural $\log$ of the number of calls $(\ln (1+\#$ of calls)) for each of the topics is used as a measure of needs for each of the topics in the past year (Landy et al., 2018).

The 2-1-1 calls are used in our research as an objective indicator of realworld needs. There are a couple of caveats to this characterization. ${ }^{3}$ The first is that phone calls are not an unadulterated measure of need, as they, in fact, reflect a mix of needs and wants. Many people have needs, but in placing a 2-1-1 call, these needs must be prioritized. In choosing to place a call, the respondent is indicating that a particular need is pressing enough to merit a phone call to 2-1-1, reflecting both the presence of a need and the caller's judgment that the problem is important. Phone calls to $2-1-1$ as an indicator of needs in the current research are analogous to the frequently used 'most important problem' question as a measure of salience. The measure, in fact, requires respondents to label an issue as a 'problem' and also requires respondents to prioritize those problems in terms of importance (Wlezien, 2005; Jennings \& Wlezien, 2011). For this reason, the current measure is an indicator of objective needs, but the measure also captures people's priorities.

The second caveat is that if policymakers' perceptions of problems are consistent with the 2-1-1 calls, it could merely reflect that policymakers rely on the phone calls as a useful indicator of a problem. However, the results below indicate that this is not likely the case, as, after controlling for city- and policymaker-characteristics, there is no evidence that the number of calls relates to policymaker perceptions, suggesting that policymakers do not rely directly on phone calls as an indicator of needs. In addition, in an online survey of policymakers from Michigan cities, although $56 \%$ of respondents report having heard of the 2-1-1 data, only $30 \%$ of this slim majority who reported being familiar with 2-1-1 claimed to use data on 2-1-1 calls to assess citizen needs. ${ }^{4}$

The data on needs in Michigan cities were matched to a survey of local policymakers fielded in the spring of 2018. The Michigan Public Policy Survey (MPPS) at the University of Michigan Center for Local, State, and Urban Policy (CLOSUP) is a survey of local policymakers throughout the state

2 Michigan 2-1-1, personal communication, May 2018.

3 We would like to thank two anonymous reviewers for raising these points.

4 The researchers collected e-mail information for 1013 policy makers for all cities in Michigan. A total of $N=117$ city policy makers responded to the online survey e-mailed to policy makers in 2018 . Study details are available upon request. Surveys conducted of Michigan residents indicate differential awareness across citizens in different regions of the state, with the greatest awareness in the Central (31\% either 'very' or 'mostly' familiar of $2-1-1)$ and Western regions (25\% 'very' or 'mostly' familiar), and the least awareness in the North (only 6\% either 'very' or 'mostly' familiar) (Michigan 2-1-1, personal communication, July 2020). 
(Center for Local, State, and Urban Policy, 2018). The key items in the survey related to perceptions of constituent needs. Respondents were asked:

First, we are interested in whether or not residents in your community need help in order to make ends meet. We'd also like to find out the extent to which those needs are being met through local resources or services (from any source, including your jurisdiction or another government, community organizations or churches, nonprofits, etc.). To the best of your knowledge, please indicate if the following are needed by residents in your community to help make ends meet and - if so - whether those needs are being met.

Response values included: Not needed in our community at all; There are needs, but all or most are being met; Some unmet needs; Significant unmet needs; Don't know.

Categories of needs in the survey included (with the corresponding category of needs from the 2-1-1 dataset listed in brackets in bold): Affordable housing [housing], Emergency housing (homeless shelters, domestic violence shelters, warming centers, etc.) [housing], Emergency food (food pantries, soup kitchens, etc. [food/meals]), Public transportation (bus or ride services, etc.) [transportation], Subsidized health care (federally qualified health centers, CHIP, Medicaid, etc.) [health care], Subsidized childcare and pre-K programs [individual, family, and community support], Job training/workforce development [employment], and Drug treatment programs [mental health/addictions]. Note that in some cases, the categories from the 2-1-1 more closely reflect the question in the survey, and housing needs were matched to two separate items in the survey (affordable housing and emergency housing needs).

Respondents were also asked to estimate the poverty rate in their district: To the best of your knowledge, approximately what percentage of people in your community do you think live under the federal poverty level (i.e., with an annual income level below $\$ 12,140$ for individuals and below $\$ 25,100$ for a family of four). Response categories included: $0-5 \%$; 6-12\%; $13-20 \% ; 21-$ $30 \% ; 31-50 \% ; 51-100 \%$; Don't know. This perception was matched to the poverty rate for the city (5-year estimates from the U.S. Census American Community Survey; https://www.census.gov/programs-surveys/acs).

Respondents were also asked about policy developments around these needs in their city. Respondents were asked: Whether or not your jurisdiction has resources or authority to implement a particular policy, which of the following, if any, have been topics of discussion within your jurisdiction's governmentincluding at Board/Council meetings - within the past 12 months? (check all that apply). The list of categories was the same as for the needs question above. Respondents were also asked about poverty programs generally: Aside from any standard property tax exemptions for residents below the 
Table 1. Descriptive statistics.

\begin{tabular}{ll}
\hline $\begin{array}{l}\text { City characteristics } \\
\text { ln(population) }\end{array}$ & $M=8.8(\mathrm{SD}=1.3) N=243$ \\
Median income (\$1000s) & $M=48.4(\mathrm{SD}=20.8) N=243$ \\
Median age & $M=38.8(\mathrm{SD}=6.1) \mathrm{N}=243$ \\
\% Minority & $M=13.9(\mathrm{SD}=16.9) \mathrm{N}=243$ \\
$\begin{array}{l}\text { Policymaker characteristics } \\
\text { Republican }\end{array}$ & $44 \% N=206$ \\
Democrat & $30 \% N=206$ \\
Nonwhite & $7 \% N=218$ \\
Age & $M=55.0(\mathrm{SD}=12.0) N=213$ \\
Highest level of education (7-point) & $M=5.1(\mathrm{SD}=1.2) N=224$ \\
\end{tabular}

Includes all policymakers who responded to at least one of the needs' perception items.

poverty level, does your jurisdiction currently have any formal local programs or policies of its own to address poverty or economic hardship in the community? Response categories included: Yes; No; Don't know.

The survey also includes self-reports of policymaker party identification (with Independents who claim be closer to one of the major parties as major party identifiers; Campbell et al., 1960), education (highest grade completed), age, and race (an indicator for nonwhite race). The dataset was matched to census data (census.gov) on the respondent's city, including median household income, median age, percent nonwhite, and population $(\ln$ (population); 2010 Census) and 5-year poverty rates (American Community Survey). Table 1 displays descriptive statistics for the sample.

\section{Results}

Perceptions of needs: bivariate analysis

Do policymaker perceptions covary with objective evidence of problems? Figure 1 displays scatterplots of perceived needs plotted against the natural $\log$ of the number of calls to 2-1-1 with a lowess regression line (bandwidth $=0.8)$ plotted for each issue. The scatterplots are jittered $(5 \%$ of the area of each scatterplot). The scatterplots are presented from the least to the most commonly perceived need (based on the percentage of respondents reporting either Some or Significant unmet needs for each category). The upper left starts with food/meals (the least commonly perceived need, with $25 \%$ of respondents reporting 'some' or 'significant unmet needs') to the most common problem, 
affordable housing (with $56 \%$ of respondents reporting 'some' or 'significant unmet needs'). ${ }^{5}$

Because perceived and actual needs are measured on different scales, Figure 1 shows evidence for covariance between the two, but cannot be used to gauge whether policymaker perceptions are, in fact, accurate. To assess accuracy, Figure 2 displays a scatterplot of city policymakers' perceived poverty rate in their city against the actual poverty rate. A larger jitter (10\% of area) is used than in Figure 1 to prevent identification of city policymakers. A lowess regression line (bandwidth $=0.8$ ) displays the relationship between actual and perceived poverty.

The results indicate a positive relationship between actual poverty and perceived poverty. For the lowest actual poverty rates up to poverty rates of about $30 \%$, the lowess line shows that the average perceived poverty rate closely matches the actual poverty rate. However, from an actual poverty rate of $30 \%$ and above, perceptions of poverty are lower than actual poverty rates. Perceived poverty rates tend to be accurate but can be severely biased downward for cities with higher levels of poverty. ${ }^{6}$

\section{Perceptions of needs: multivariate analysis}

Table 2 presents OLS regression results of perceived poverty regressed on actual poverty rate (Model 1) or perceived need (for each of eight issues from the 2-1-1 data) regressed on the logged number of calls $\ln (1+$ number of calls)) for each need listed. Each model includes controls for natural log of city population and policymaker party (indicators for Democrat and Republican, with Independent/other as the baseline category). The models are estimated with robust standard errors clustered by city. The table also displays F-tests for a comparison of the coefficients for Republican and

5 To provide context for the extent of the problems listed, the percentage of respondents reporting that there are 'some' or 'significant unmet' needs is as follows: food $(25 \%)$, health care $(35 \%)$, child care $(37 \%)$, emergency housing $(38 \%)$, transportation $(43 \%)$, job training $(50 \%)$, drug training $(55 \%)$, and affordable housing $(56 \%)$. The poverty rate in 2018 in Michigan was $15 \%$.

6 One concern about the poverty results is that respondents, in completing the multiple choice survey item about the poverty rate, may have simply looked up the poverty rate, meaning that the current results overstate the congruence between perceived and actual poverty. There are a number of reasons that these concerns may not be as important as they appear. First, respondents are carefully and clearly informed that the CLOSUP survey results are anonymous, limiting the incentive to cheat. Second, survey respondents typically act as 'satisficers' (Krosnick et al., 1996), exerting limited effort in completing surveys, which would preclude taking the time to look up answers. Third, research on venue effects, where some venues (e.g., online surveys) offer opportunities for cheating find no venue effect for multiple choice items about political knowledge (Shulman \& Boster, 2014). Finally, the pattern of results for poverty are similar to the other types of needs that would be more difficult to look up. 


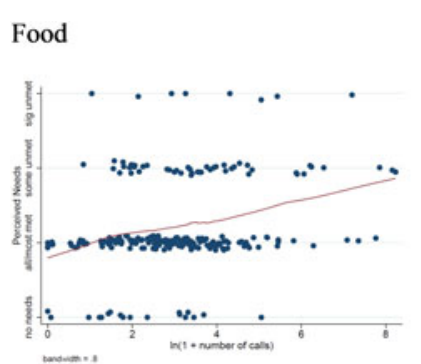

Transportation

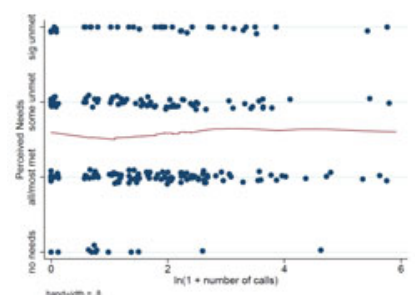

Healthcare

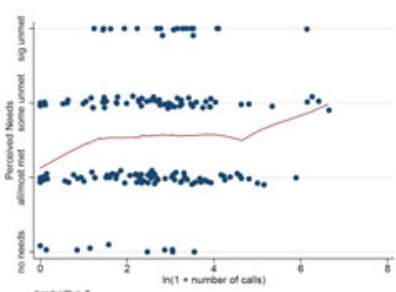

Job Training

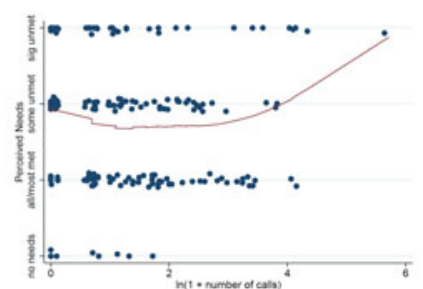

Child Care

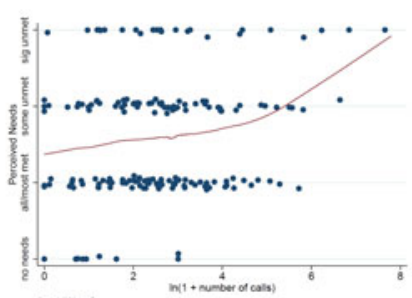

Drug treatment

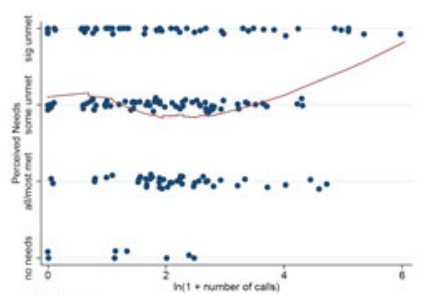

Emergency housing

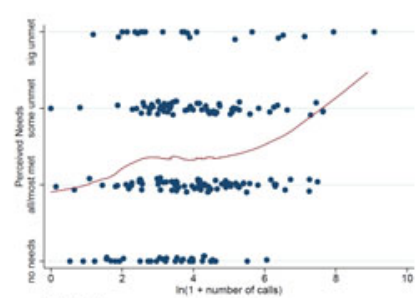

Affordable Housing

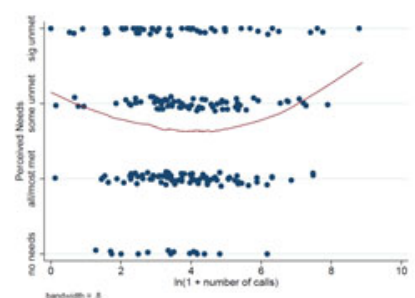

Figure 1. Lowess estimates of policymaker responsiveness to needs. 


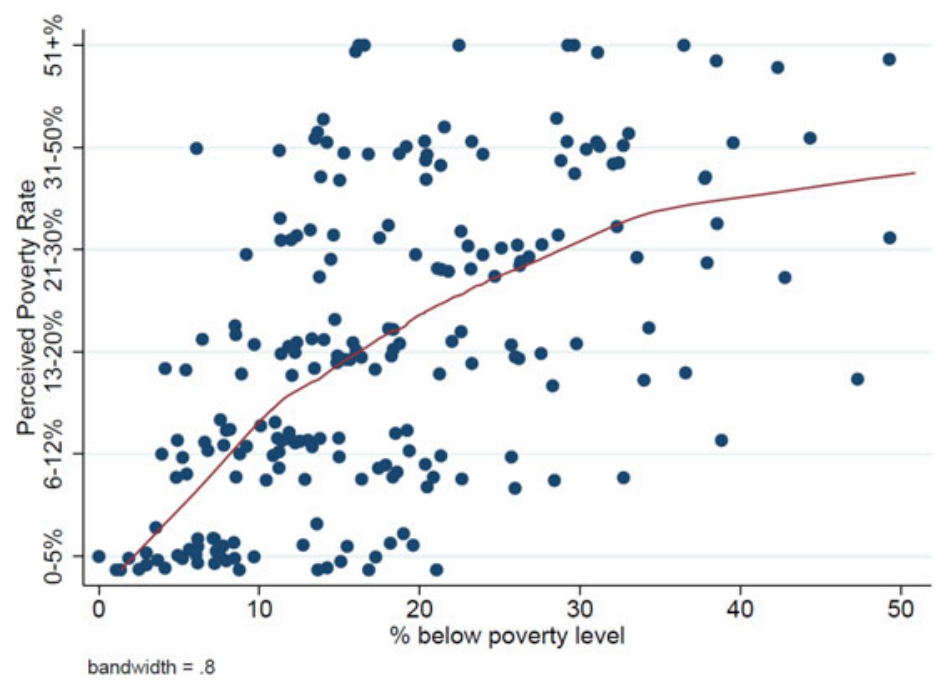

Figure 2. Lowess estimates of policymaker responsiveness to poverty.

Democratic identification. As in Figure 1, the needs are displayed from the least to the most commonly perceived.

For most of the regressions, there is a positive, statistically significant relationship between actual need and perceived need. For models 2-5, for each unit increase in the logged number of calls, perceived needs increase by $0.1-$ 0.2 points on the four-point scale. For most of the remaining models, the estimated coefficient of actual needs is positive but not statistically significant. ${ }^{7}$

Despite evidence of covariance between perceived and actual needs, Democratic and Republican policymakers have different perceptions of the prevalence needs in across a number of issues, with Democrats generally having perceptions of greater needs in their city. With the exception of Model 1 (poverty), Democrats have higher perceptions of the prevalence of needs. For two of the eight needs (health care and child care), the estimated differences are statistically significant (as indicated by the F-tests at the bottom of the table), and for another two (job training and affordable housing), the estimated differences are close to statistical significance.

Table 3 presents the same set of regressions with the addition of controls for policymaker characteristics, including education (highest grade completed), age, age squared, and race (nonwhite). The models also include controls for

7 An alternate method, using ordered logit regression, produces comparable results (Appendix Table A1). 
Table 2. Policymaker perceptions and citizen needs.

\begin{tabular}{|c|c|c|c|c|c|c|c|c|c|}
\hline Model \# & Poverty & Food & Health care & Child care & $\begin{array}{l}5 \\
\text { Emergency } \\
\text { housing }\end{array}$ & Transportation & Job training & $\begin{array}{l}8 \\
\text { Drug } \\
\text { treatment }\end{array}$ & $\begin{array}{l}9 \\
\text { Affordable } \\
\text { housing }\end{array}$ \\
\hline $\begin{array}{l}\text { Poverty rate } \\
\text { (5-year ACS) }\end{array}$ & $0.08 *(0.01)$ & - & - & - & - & - & - & - & - \\
\hline $\ln (1+$ calls $)$ & - & $0.12 *(0.04)$ & $0.21 *(0.06)$ & $0.11(0.07)$ & $0.22 *(0.07)$ & $0.02(0.06)$ & $0.03(0.10)$ & $0.10(0.09)$ & $0.00(0.07)$ \\
\hline $\ln$ (population) & $-0.06(0.07)$ & $-0.08(0.06)$ & $-0.22(0.07)^{*}$ & $-0.09(0.08)$ & $-0.25(0.09)$ & $-0.00(0.06)$ & $-0.13(0.09)$ & $-0.19 *(0.08)$ & $-0.05(0.09)$ \\
\hline Republican & $-0.01(0.25)$ & $-0.19(0.11)$ & $-0.25(0.15)$ & $-0.44 *(0.17)$ & $-0.01(0.15)$ & $-0.00(0.14)$ & $-0.24(0.16)$ & $-0.12(0.18)$ & $-0.22(0.15)$ \\
\hline Democrat & $-0.14(0.24)$ & $-0.12(0.12)$ & $0.24(0.16)$ & $-0.10(0.17)$ & $0.11(0.16)$ & $0.19(0.16)$ & $0.04(0.18)$ & $0.06(0.20)$ & $0.07(0.16)$ \\
\hline Constant & $2.0(0.75)$ & $2.6(0.42)$ & $4.0(0.48)$ & $3.3(0.56)$ & $3.7(0.60)$ & $2.5(0.59)$ & $4.0(0.71)$ & $4.5(0.59)$ & $3.2(0.56)$ \\
\hline$N$ & 186 & 189 & 154 & 150 & 179 & 193 & 170 & 157 & 194 \\
\hline$R^{2}$ & 0.34 & 0.07 & 0.14 & 0.08 & 0.06 & 0.01 & 0.04 & 0.04 & 0.02 \\
\hline $\begin{array}{l}\text { F-statistic } \\
\text { (p-value) } H_{\mathrm{A}} \text { : } \\
\quad D \neq R\end{array}$ & $0.40(0.53)$ & $0.49(0.48)$ & $14.3 *(0.00)$ & $5.76^{*}(0.02)$ & $0.55(0.46)$ & $1.57(0.21)$ & $3.27(0.07)$ & $1.31(0.25)$ & $3.47(0.06)$ \\
\hline
\end{tabular}

* $\mathrm{p}<0.05$, two-tailed. Robust standard errors clustered by city in parentheses. 


\begin{tabular}{|c|c|c|c|c|c|c|c|c|c|}
\hline Model \# & $\begin{array}{l}1 \\
\text { Poverty }\end{array}$ & $\begin{array}{l}2 \\
\text { Food }\end{array}$ & $\begin{array}{l}3 \\
\text { Health care }\end{array}$ & Child care & $\begin{array}{l}5 \\
\text { Emergency } \\
\text { housing }\end{array}$ & Transportation & $\begin{array}{l}7 \\
\text { Job training }\end{array}$ & $\begin{array}{l}8 \\
\text { Drug } \\
\text { treatment }\end{array}$ & $\begin{array}{l}9 \\
\text { Affordable } \\
\text { housing }\end{array}$ \\
\hline $\begin{array}{l}\text { Poverty rate } \\
\text { (5-year ACS) }\end{array}$ & $0.05 *(0.02)$ & - & - & - & - & - & - & - & - \\
\hline $\ln (1+$ calls $)$ & - & $0.07(0.05)$ & $0.05(0.07)$ & $-0.03(0.08)$ & $0.06(0.08)$ & $-0.01(0.06)$ & $-0.07(0.12)$ & $-0.07(0.10)$ & $-0.09(0.08)$ \\
\hline $\ln$ (population) & $-0.02(0.10)$ & $0.02(0.07)$ & $-0.05(0.09)$ & $0.12(0.09)$ & $-0.10(0.09)$ & $-0.02(0.08)$ & $0.03(0.10)$ & $0.01(0.10)$ & $0.11(0.11)$ \\
\hline Republican & $0.03(0.26)$ & $-0.20(0.11)$ & $-0.27(0.16)$ & $-0.37^{*}(0.17)$ & $-0.02(0.16)$ & $0.09(0.16)$ & $-0.21(0.16)$ & $-0.05(0.18)$ & $-0.16(0.14)$ \\
\hline Democrat & $-0.01(0.25)$ & $-0.09(0.12)$ & $0.13(0.16)$ & $-0.02(0.17)$ & $0.07(0.17)$ & $0.13(0.18)$ & $0.04(0.16)$ & $0.07(0.19)$ & $0.17(0.16)$ \\
\hline Nonwhite & $-0.13(0.43)$ & $-0.22(0.19)$ & $-0.23(0.19)$ & $-0.42(0.27)$ & $-0.40(0.33)$ & $-0.07(0.20)$ & $-0.36(0.28)$ & $-0.42(0.26)$ & $0.03(0.32)$ \\
\hline Age & $-0.07(0.05)$ & $0.00(0.00)$ & $0.00(0.03)$ & $0.04(0.03)$ & $0.07(0.04)$ & $-0.01(0.04)$ & $-0.08(0.04)$ & $-0.01(0.04)$ & $0.04(0.04)$ \\
\hline $\mathrm{Age}^{2}$ & $0.00(0.00)$ & $0.00(0.00)$ & $0.00(0.00)$ & $0.00(0.00)$ & $0.00(0.00)$ & $0.00(0.00)$ & $0.00(0.00)$ & $0.00(0.00)$ & $0.00(0.00)$ \\
\hline Education & $-0.02(0.09)$ & $0.05(0.03)$ & $0.00(0.05)$ & $0.04(0.05)$ & $0.04(0.06)$ & $0.00(0.06)$ & $0.08(0.05)$ & $0.04(0.06)$ & $0.10 *(0.05)$ \\
\hline $\begin{array}{l}\text { Median income } \\
(\$ 1000 \mathrm{~s})\end{array}$ & $-0.02 *(0.00)$ & $-0.01 *(0.00)$ & $-0.02 *(0.00)$ & $-00.02 *(0.00)$ & $-0.02 *(0.00)$ & $-0.02 *(0.00)$ & $-0.02 *(0.00)$ & $-0.02 *(0.00)$ & $-0.02 *(0.00)$ \\
\hline Median age & $-0.01(0.02)$ & $0.00(0.01)$ & $0.00(.01)$ & $.02(.01)$ & $.00(.01)$ & $.00(.01)$ & $.02(.01)$ & $.02(.01)$ & $.01(.01)$ \\
\hline$\%$ Minority & $-.06(.92)$ & $-.26(.37)$ & $.015(.38)$ & $-0.64(0.43)$ & $0.54(0.54)$ & $0.65(0.50)$ & $-0.18(0.62)$ & $0.29(0.43)$ & $-0.82(0.54)$ \\
\hline Constant & $5.9(2.1)$ & $2.1(.89)$ & $4.1(1.2)$ & $1.5(1.2)$ & $2.0(1.38)$ & $3.4(1.4)$ & $5.0(1.4)$ & $3.3(1.6)$ & $1.4(1.3)$ \\
\hline$N$ & 174 & 179 & 147 & 143 & 171 & 183 & 162 & 150 & 184 \\
\hline$R^{2}$ & 0.37 & 0.18 & 0.28 & 0.33 & 0.18 & 0.05 & 0.24 & 0.18 & 0.14 \\
\hline $\begin{array}{l}\text { F-statistic } \\
\text { (p-value) } H_{\mathrm{A}}: \\
D \neq R\end{array}$ & $0.04(0.84)$ & $1.04(0.31)$ & $10.0 *(0.00)$ & $7.53 *(0.01)$ & $0.31(0.58)$ & $0.08(0.78)$ & $2.81(0.10)$ & $0.64(0.42)$ & $4.58 *(0.03)$ \\
\hline
\end{tabular}

" $\mathrm{p}<0.05$, two-tailed. Robust standard errors clustered by city in parentheses. 
city characteristics, including median household income, median age, and percent nonwhite. ${ }^{8}$ With the inclusion of controls, the coefficients for objective indicators of problems (aside from the poverty rate) are no longer statistically significant. Rather than being directly related to needs, policymakers' judgments appear to be based on community characteristics - in particular, median household income, which is negative and statistically significant in all of the models. However, it is noteworthy that the $R^{2}$ from the models is relatively low, with between 5\% (transportation) and 37\% (poverty) of the variance in perceptions accounted for by the predictors in the model. This indicates that although median income may provide indirect information about the extent of a variety of needs, using this heuristic still leaves a high degree of uncertainty.

This uncertainty may contribute to partisan differences in perceptions of needs. The results from Table 3 demonstrate the robustness of the difference between Democrats and Republicans in perceptions of needs. The coefficients for policymaker partisanship from Table 3 are plotted in Figure 3, ordered from the greatest differences between the parties (health care) to the least (public transportation). (Perceptions of poverty are excluded as this item is measured on a different scale. For this item, Republicans unexpectedly perceive greater levels of need than Democrats, although the difference is not statistically significant.) The results show that Democrats consistently perceive greater needs than Republicans after controlling for a variety of policymaker and city characteristics.

\section{Assessing the validity of the indicators of needs}

The regression-based evidence presented in Table 3 suggests that policymakers use city median income to make inferences about the prevalence of constituent needs. ${ }^{9}$ Regression models presented in Table 4 suggest that median income is

8 The results are substantively similar if the poverty rate is added as a control for Models 2-9 (results available upon request).

9 Other analyses explore a number of potential moderators of the relationship between objective indicators and perceptions (Appendix Table A2). In the first set of models, the indicators were interacted with the respondent's perceived quality of interaction between policy makers and constituents (Miler, 2007; Bergan, 2009; Bergan \& Cole, 2015; Broockman \& Skovron, 2018). (Thinking more generally about the tone of discussion and communication that takes place around local policy issues, how would you describe the general state of public discourse between the following groups within your jurisdiction? [Between elected officials and residents]:Very Constructive, Somewhat Constructive, Mixed, Somewhat Divisive, Very Divisive, Don't Know.) Two sets of regressions add interactions for indicators and city characteristics (the natural log of population and percent minority, respectively) as city size and diversity may weaken the relationship between problems and perceptions. The final set of regressions includes interactions for indicators and indicators for 

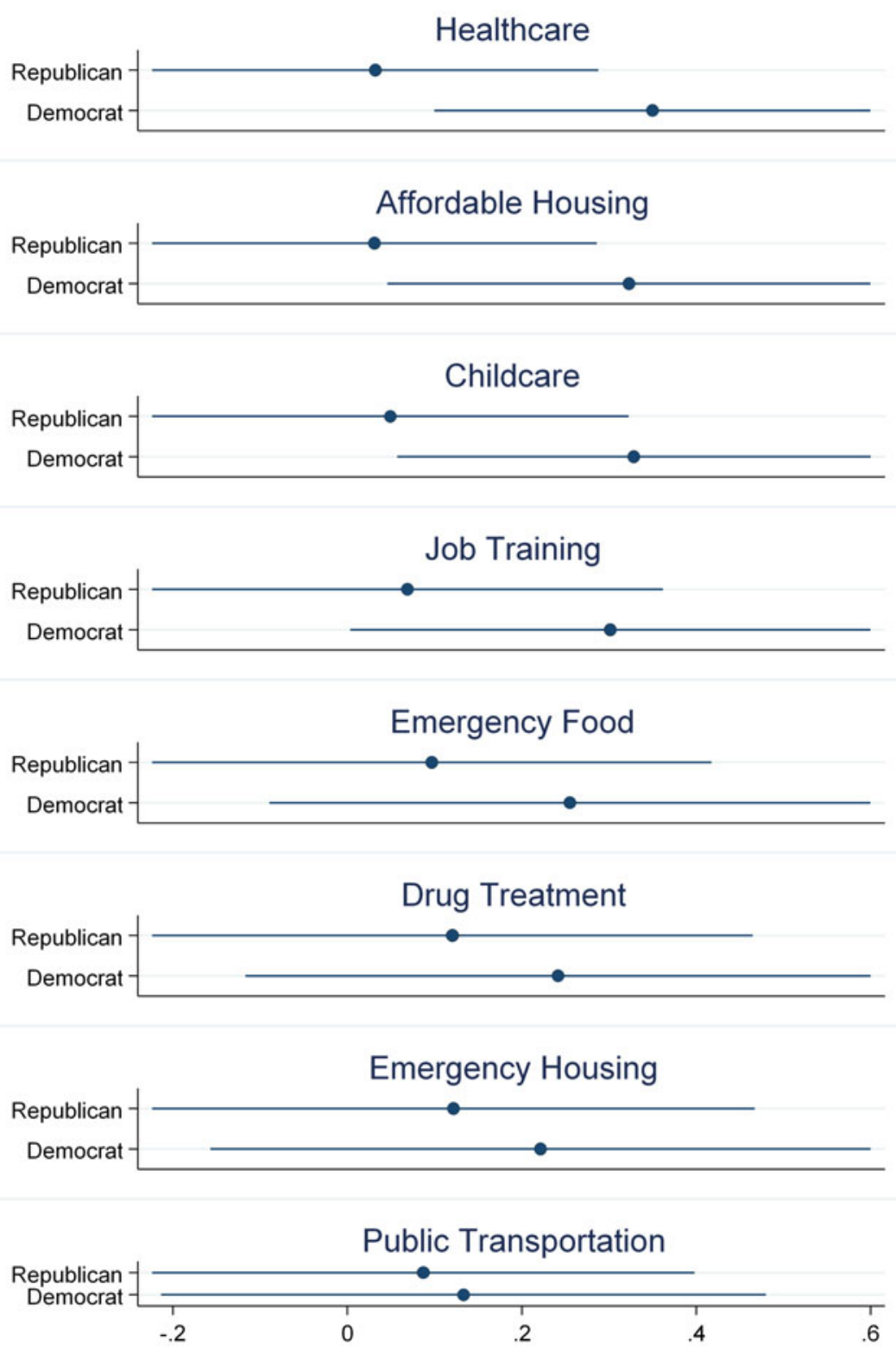

Figure 3. Regression estimates of party affiliation on perceptions of needs. Notes: Baseline $=$ Pure Independents. 95\% error bars. Coefficient estimates from Table 2 . 
Table 4. Accuracy of policymaker poverty perceptions.

\begin{tabular}{|c|c|c|c|}
\hline \multirow[b]{3}{*}{ Model \# } & \multicolumn{2}{|l|}{1} & \multirow{2}{*}{$\frac{2}{\text { Logit estimates }}$} \\
\hline & \multicolumn{2}{|c|}{ Multinomial logit estimates } & \\
\hline & Overestimate & Underestimate & Accurate \\
\hline $\ln$ (population) & $0.29(0.21)$ & $0.29(0.19)$ & $-28(0.17)$ \\
\hline Republican & $-0.41(0.53)$ & $-0.07(0.53)$ & $0.23(0.46)$ \\
\hline Democrat & $-0.04(0.55)$ & $-.14(0.55)$ & $0.06(0.49)$ \\
\hline Nonwhite & $0.61(0.89)$ & $0.42(1.0)$ & $-0.56(0.87)$ \\
\hline Age & $-0.05(0.12)$ & $-0.02(0.12)$ & $0.04(0.10)$ \\
\hline $\mathrm{Age}^{2}$ & $0.00(0.00)$ & $0.00(0.00)$ & $-0.00(0.00)$ \\
\hline Education & $-0.25(0.16)$ & $-0.40 *(0.14)$ & $0.31 *(0.13)$ \\
\hline Median income (\$1000s) & $-0.03 *(0.01)$ & $-0.02 *(0.00)$ & $0.02 *(0.00)$ \\
\hline Median age & $-0.02(0.04)$ & $-0.03(0.03)$ & $0.02(0.03)$ \\
\hline$\%$ Minority & $-2.2(1.7)$ & $-5.0 *(2.0)$ & $3.1(1.6)$ \\
\hline Constant & $2.0(3.9)$ & $3.2(3.9)$ & $-3.4(3.3)$ \\
\hline$N$ & 174 & 174 & \\
\hline Pseudo- $R^{2}$ & 0.07 & 0.08 & \\
\hline
\end{tabular}

* $\mathrm{p}<0.05$, two-tailed. Robust standard errors clustered by city in parentheses.

indeed a valid predictor of needs. The table presents results from a set of regressions for the cities in the sample using city characteristics (population, median income, median age, and percent minority) to predict needs. Median income consistently predicts city needs, with negative and statistically significant coefficients across all needs explored in the dataset. Although median income consistently predicts needs, it is not always the strongest predictor for any given need. For example, percent minority is a strong predictor of a number of needs listed (poverty, food, housing, job training, and drug treatment), but it is not a strong predictor of the remaining needs. In addition, although using median income may be a simple approach to forming roughly accurate perceptions of needs in the city, and median income may be among the strongest indirect indicators of needs in a city, using this 'one-reason' approach in this context does not necessarily lead to precise predictions, as indicated by the low $R^{2}$ of the regression results predicting perceptions of citizen needs in Table 3 . The results suggest that the absence of direct evidence of citizen needs, using results do not provide consistent evidence that any of the policymaker or city characteristics moderate the influence of objective conditions on perceptions. 
median income to make a judgment, is a valid, low-cost method for making judgments about a variety of needs, but falls far short of providing highly precise estimates of any specific citizen need.

Which policymakers have most accurate perceptions of poverty? Because poverty perceptions and the poverty rate are measured on the same scale, we were able to create two measures of accuracy for poverty perceptions. In the first, accurate perceptions are coded as 0 ( $N=82$ or $38.7 \%$ of responses), overestimates as $1(N=66,31.1 \%)$, and underestimates as $2(N=64,30.2 \%)$. We explored the effects of city and policymaker characteristics on this measure of accuracy with a multinomial logit model with accurate perceptions serving as the baseline category. A second measure is a binary variable, coded 1 for accurate perceptions and 0 otherwise (either over- or underestimates). We estimated the effects of city and policymaker characteristics on accuracy with a logit model. The results are displayed in Table 5 .

Model 1 displays the results for over- and underestimates relative to a baseline category. The signs for every one of the coefficients are the same for both over- and underestimates, suggesting that factors that contribute to errors do not consistently lead to bias. For this reason, the current discussion focuses on Model 2, which predicts 'accuracy' with the baseline of 0 for either overor underestimates. The coefficient for education is positive and statistically significant. That is, policymakers with higher levels of education are more likely to have accurate perceptions of poverty in their city. The results suggest that cognitive factors could play a role in accurate perceptions of needs. This is not an entirely surprising finding, but cognitive differences across policymakers could be more deeply explored in the policymaking literature. The coefficient for income is positive and statistically significant. None of the other coefficients are statistically significant, although percent minority in a city is large and approaches statistical significance.

\section{Perceptions of needs and policy making}

The relationship between indicators of needs and policymaker perceptions suggests that policymaker perceptions covary with real-world concerns. Are policy deliberations and policy outcomes responsive to citizen needs? We explore these questions with regression analyses displayed in Table 4, estimating the relationship to objective indicators with policymaker reports of policy deliberations about each of the specific problems. For each of the eight issues, respondent reports of city council discussions about needs are regressed on indicators of constituent needs and the control variables. The results do not provide any evidence that objective needs translate into policy deliberations: the coefficients are all small and not statistically significant. 
Table 5. Predicting needs with selected city characteristics.

\begin{tabular}{|c|c|c|c|c|c|c|c|c|}
\hline Model \# & $\begin{array}{l}1 \\
\text { Poverty }\end{array}$ & $\begin{array}{l}2 \\
\text { Food }\end{array}$ & $\begin{array}{l}3 \\
\text { Health care }\end{array}$ & $\begin{array}{l}4 \\
\text { Child care }\end{array}$ & $\begin{array}{l}5 \\
\text { Housing }\end{array}$ & $\begin{array}{l}6 \\
\text { Transportation }\end{array}$ & $\begin{array}{l}7 \\
\text { Job training }\end{array}$ & $\begin{array}{l}8 \\
\text { Drug treatment }\end{array}$ \\
\hline $\ln$ (population) & $-1.26 *(0.37)$ & $0.86 *(0.06)$ & $0.90 *(0.05)$ & $0.87 *(0.05)$ & $0.93 *(0.05)$ & $0.77 *(0.06)$ & $0.70 *(0.05)$ & $0.77 *(0.05)$ \\
\hline $\begin{array}{l}\text { Median } \\
\text { income } \\
(\$ 1000 s)\end{array}$ & $-0.29 *(0.04)$ & $-0.37 *(0.08)$ & $-0.028 *(0.004)$ & $-0.002 *(0.004)$ & $-0.022 *(0.003)$ & $-0.024 *(0.003)$ & $-0.011 *(0.003)$ & $-0.015 *(0.003)$ \\
\hline Median age & $-0.37 *(0.08)$ & $19.5 *(3.3)$ & $0.003(0.013)$ & $0.005(0.012)$ & $-0.026 *(0.011)$ & $-0.003(0.011)$ & $0.012(0.008)$ & $-0.015(0.010)$ \\
\hline$\%$ Minority & $19.5 *(3.3)$ & $54.6(4.3)$ & $0.19(0.31)$ & $1.57(0.012)$ & $1.35 *(0.34)$ & $0.163(0.36)$ & $1.77 *(0.30)$ & $0.66 *(0.28)$ \\
\hline Constant & $54.6(4.3)$ & $-2.53(0.77)$ & $-4.15(0.68)$ & $-4.27(0.67)$ & $-2.52(0.66)$ & $-3.79(0.711)$ & $-5.16(0.49)$ & $-3.67(0.58)$ \\
\hline$N$ & 237 & 228 & 228 & 228 & 228 & 228 & 228 & 228 \\
\hline$R^{2}$ & 0.65 & 0.69 & 0.64 & 0.66 & 0.74 & 0.57 & 0.74 & 0.69 \\
\hline
\end{tabular}

* $\mathrm{p}<0.05$, two-tailed. Robust standard errors in parentheses. 
An alternate pair of models, presented in Table 5, explores whether needs predict the presence of poverty-related programs. The self-reported measure of programs to address poverty is regressed on (1) percent under the poverty level in the district and (2) perceived poverty, respectively. Both of these coefficients are small and not statistically significant. Again, there is no evidence that objective needs or perceptions of needs contribute to actual policy outcomes.

\section{Discussion}

The current results suggest that policymaker perceptions of constituent needs covary with actual needs and provide some evidence that perceptions of needs are accurate (Tables 6 and 7). The results provide some evidence that policymakers are capable of acting as trustees, as they form judgments that reflect problems in their communities. The analyses also suggest that policymakers form judgments based on a 'one-reason decision making' strategy (Gigerenzer \& Gaissmaier, 2011), using income to assess the extent of constituent needs. This finding lends some detail to prior claims about bounded rationality in policy making, suggesting a specific heuristic that policymakers use to form judgments. Jones and Baumgartner (2005) use a simulation to show that when policymakers apply different weights to indicators of problems, a nonnormal distribution of shifts in policy results, consistent with the empirical evidence on the distribution of policy changes over time. The assumption that policymakers apply different weights to indicators would be compatible with the current results, as policymakers overweight a single indicator (median income) and ignore most other factors in forming a judgment. The use of one indicator could lead to reasonable - if somewhat biased and imprecise - perceptions of a problem most of the time. However, the inaccuracy of these perceptions could increase if the problem intensified beyond what would be expected based on the indicator used, as illustrated by the example of increasing homelessness in California during a period of economic growth. In the event of a crisis, policymakers, with greater attention to the issue, and, in turn, a more varied collection of indicators of the problem, could readjust their perceptions.

There are some caveats to the claim that policymakers' perceptions are generally accurate and covary with problems. First, there is some evidence of bias in perceptions, with policymakers underestimating high rates of poverty. This bias is particularly large for cities facing higher than average levels of poverty. Second, the relationship between actual and perceived needs is not particularly strong: the $R^{2}$ for each of the models predicting perceived with actual needs is relatively low, with typically less than $10 \%$ of the variance being accounted for by objective conditions and controls for population and policymaker party. 
Table 6. Policymaker deliberations about citizen needs.

\begin{tabular}{|c|c|c|c|c|c|c|c|c|}
\hline Model \# & $\begin{array}{l}1 \\
\text { Food }\end{array}$ & $\begin{array}{l}2 \\
\text { Health care }\end{array}$ & $\begin{array}{l}3 \\
\text { Child care }\end{array}$ & $\begin{array}{l}4 \\
\text { Emergency housing }\end{array}$ & $\begin{array}{l}5 \\
\text { Transportation }\end{array}$ & $\begin{array}{l}6 \\
\text { Job training }\end{array}$ & $\begin{array}{l}7 \\
\text { Drug treatment }\end{array}$ & $\begin{array}{l}8 \\
\text { Affordable housing }\end{array}$ \\
\hline $\ln (1+$ calls $)$ & $-0.00(0.03)$ & $0.03(0.02)$ & $-0.02(0.02)$ & $0.00(0.04)$ & $-0.07 *(0.03)$ & $0.07(0.05)$ & $-0.07(0.05)$ & $0.02(0.04)$ \\
\hline Constant & $-0.12(0.27)$ & $0.35(0.19)$ & $0.04(0.17)$ & $-0.48(0.28)$ & $-0.26(0.31)$ & $0.86(0.39)$ & $-0.51(0.36)$ & $-0.49(0.28)$ \\
\hline$N$ & 160 & 160 & 160 & 160 & 160 & 160 & 160 & 160 \\
\hline$R^{2}$ & 0.03 & 0.06 & 0.05 & 0.05 & 0.07 & 0.05 & 0.04 & 0.01 \\
\hline
\end{tabular}

* $\mathrm{p}<0.05$, two-tailed. Robust standard errors clustered by city in parentheses. Models include controls for population and respondent party (not displayed). 
Table 7. Programs addressing citizen needs.

\begin{tabular}{lcc}
\hline \hline \multirow{2}{*}{ Model \# } & 1 & 2 \\
\hline Poverty & Poverty programs & Poverty programs \\
Perceived poverty & $-0.00(0.00)$ & - \\
Constant & - & $-0.02(0.03)$ \\
$N$ & $-0.93(0.21)$ & $-0.97(0.21)$ \\
$R^{2}$ & 191 & 180 \\
& 0.16 & 0.16 \\
\hline \hline
\end{tabular}

* $\mathrm{p}<0.05$, two-tailed. Robust standard errors clustered by city in parentheses. Models include controls for population and respondent party (not displayed).

The results suggest that although the 'one-reason' approach seems to generally provide unbiased estimates that are responsive to increases in needs, using median income as an indicator should not be considered a close approximation of possessing direct, accurate information about the prevalence of needs in the population.

Third, Republican and Democratic policymakers differ in their perceptions, with Democrats consistently perceiving more unmet needs than Republicans. This may be in part due to uncertainty stemming from using indirect indicators to assess needs: using median income to make a judgment about the level of needs allows policymakers to arrive at assessments of needs that fit with their political predispositions. As discussed above, 2-1-1 calls may represent a mixture of objective needs as well as priorities over these needs. A difference in perceptions among policymakers from each major party could represent differential perceptions in either needs or priorities. ${ }^{10}$ For example, in exhibiting differing perceptions of needs for emergency housing, Democrats may perceive great objective needs than Republicans or, alternatively, may place greater weight on constituent priorities over these needs (or both). ${ }^{11}$

Despite these caveats, policymaker perceptions reflect citizen needs. However, the relationship between perceptions and needs does not translate into actual policies. For none of the issues listed were either policy discussions or actual programs more likely to emerge with objective increases in social

10 We would like to thank an anonymous reviewer for this interpretation.

11 Another explanation is that city council members may be either at-large members or represent specific wards in their city. For this reason, even policy makers from the same city may represent different constituents and could have different perceptions of needs based on their experiences with constituents or in weighting the needs of their own ward more heavily in forming perceptions. This possibility may explain partisan differences, but cannot be directly evaluated with the survey data available (we thank an anonymous reviewer for this suggestion). 
problems. Although prior theorizing about the policy process has emphasized bounded rationality at the level of the individual policymaker, it appears that aggregate features of the policymaking context may contribute to a lack of policy responsiveness. For example, policymakers may consider addressing the problems listed as beyond their city's capacity or beyond the scope of local government. In addition, features of policy making in the aggregate, including ambiguity concerning aggregate preferences and goals (Cohen et al., 1972) and institutional friction (Jones \& Baumgartner, 2005), may inhibit the responsiveness of policies to citizen needs. These and other aggregate features of the policymaking process, rather than individual misperceptions, may be responsible for a failure of local responsiveness to constituent needs.

There is a long history of studying the relationship between preferences and policy outcomes, but there has been much less work on the relationship between needs and policy outcomes. The current work is one step in attempting to address this gap in the literature. A number of normative issues are raised by the analysis. Which is more important: addressing objective needs or responding to preferences? Should policymakers address needs when doing so would conflict with majority preferences? Should policymakers attend to needs when the public does not prioritize doing so? These are normative questions that echo classic debates about the trustee versus delegate models of representation (Pitkin, 1967; Mansbridge, 2003; Rehfeld, 2009) and are beyond the scope of this article. However, a precondition for addressing needs, and of weighing preferences versus needs, is for policymakers to accurately perceive needs. The current study suggests that for most needs, perceptions are roughly accurate, but as policymakers rely on heuristics, these perceptions are not very precise. Using heuristics would appear to preclude a highly refined weighting of needs. Perhaps a more relevant set of normative questions, a step removed from weighing actual needs, concerns the role of different types of heuristics in informing priorities. How should policymakers prioritize different potential heuristics when evaluating potential problems? For example, the current set of results suggests that policymakers rely on median income, a rather crude indicator for a host of needs that are important mostly for people of lower socioeconomic status. Do policymakers rely on more finely grained or a greater number of heuristics for needs that affect constituents with higher socioeconomic status? Future normative work could explore the number and quality of heuristics used in forming perceptions of needs, and how features of commonly employed heuristics differ across different types of needs affecting different populations. 


\section{Conclusion}

The current analysis uses a unique dataset to explore policymaker perceptions of needs in their community, finding that perceptions reflect actual needs, and suggesting that policymakers are capable of acting as trustees. There is evidence that policymakers use valid indicators to form assessments of needs, although these assessments, based on indirect indicators of need, leave some uncertainty, leading to rather imprecise predictions and differing perceptions across members of either major party.

There are a number of limitations to the current analysis. The current study of local policymakers may or may not be relevant to other jurisdictions. What about state and federal policymakers? One possibility is that state and federal officials do not have to rely as heavily on heuristics as they have access to other data sources, including interactions with group representatives, polling, and other forms of evidence about needs. Another possibility is that state and federal officials rely on the same strategies as local officials, using indicators (such as median income) to make judgments about needs. Policymaking research, drawing on theories of bounded rationality, suggests that federal policymakers have limited cognitive resources to pay attention to problems (Jones \& Baumgartner, 2005) and rely on indicators to make judgments about problems (Kingdon, 1984). This heuristic approach could be less effective at the state or national level than at the local level as this approach may lead to less accurate perceptions with larger, more heterogeneous communities. Future research should explore to what extent state and federal policymakers consistently rely on rigorous data in judging needs.

A number of the needs explored in the current article (such as emergency housing or food) may be accurately assessed using demographic characteristics such as median income, whereas other types of needs may be harder to assess based on income (or any other single indicator). In addition, images of the poor are related to personal responsibility frames (Rose \& Baumgartner, 2013), which could lead to differences in perceptions of needs between policymakers from the two major parties. Future work should explore the generalizability of the results to other types of needs.

The current analyses explore the influence of a host of city characteristics on perceptions, concluding that policymakers use median income as a heuristic about the extent of needs in the community. These analyses, although suggestive, use indirect methods to explore how policymakers learn about their district. Future work should use alternate methods to more directly assess what information sources policymakers use to learn about the problems that their constituents face. Some field experimental research suggests alternate methods to explore the influence of communications from constituents 
(Bergan, 2009; Bergan \& Cole, 2015) and polling information (Butler \& Nickerson, 2011; Kalla \& Porter, 2019) on policymaker behaviors. Future work could expand on these efforts to explore influences on policymaker perceptions of citizen needs to provide a greater understanding of bounded rationality and how problems influence - or fail to influence - policy outcomes.

\section{Acknowledgments}

The authors would like to thank Gustavo Rotandaro from Michigan 2-1-1 for providing data and assistance. The authors would like to thank two anonymous reviewers for feedback that greatly improved the manuscript.

\section{References}

Ackrill, R., Kay, A., and N. Zahariadis (2013), 'Ambiguity, multiple streams, and EU policy', Journal of European Public Policy, 20(6): 871-887.

Baumgartner, F. R., and B. D. Jones (1993), Agendas and Instability in American politics, Chicago: University of Chicago Press.

Bendor, J. (2003), 'Herbert A. Simon: Political scientist', Annual Review of Political Science, 6(1): 433-471.

Bergan, D. E. (2009), 'Does grassroots lobbying work? A field experiment measuring the effects of an e-mail lobbying campaign on legislative behavior', American Politics Research, 37(2): $327-352$.

Bergan, D. E. and R. T. Cole (2015), 'Call your legislator: A field experimental study of the impact of a constituency mobilization campaign on legislative voting', Political Behavior, 37(1): 27-42.

Brighton, H. and G. Gigerenzer (2011), 'Towards competitive instead of biased testing of heuristics: A reply to Hilbig and Richter (2011)', Topics in Cognitive Science, 3(1): 197-205.

Broockman, D. E. and C. Skovron (2018), 'Bias in perceptions of public opinion among political elites', American Political Science Review, 112(3): 542-563.

Brunswik, E. (1952), The conceptual framework of psychology. Chicago, IL: University of Chicago Press.

Burstein, P. (2003), 'The impact of public opinion on public policy: A review and an agenda', Political Research Quarterly, 56(1): 29-40.

Butler, D. M., and D. E. Broockman (2011), 'Do politicians racially discriminate against constituents? A field experiment on state legislators', American Journal of Political Science, 55(3): 463-477.

Butler, D. M. and D. W. Nickerson (2011), 'Can learning constituency opinion affect how legislators vote? Results from a field experiment', Quarterly Journal of Political Science, 6(1): 55-83.

Campbell, A., P. E. Converse, W. E. Miller, and D. E. Stokes (1960), The American voter, New York: Wiley.

Carpenter, C. J. (2019), 'Cognitive dissonance, ego-involvement, and motivated reasoning', Annals of the International Communication Association, 43(1): 1-23.

Center for Local, State, and Urban Policy (2018), The Michigan public policy survey (Spring 2018) [Data set]. University of Michigan [Producer and Distributor]. Retrieved from: http://closup. umich.edu/.

Cohen, M. D., J. G. March and J. P. Olsen (1972), 'A garbage can model of organizational choice', Administrative Science Quarterly, 17(1): 1-25.

Dearing, J. W. and E. Rogers (1996), Agenda-setting, Thousand Oaks: Sage Publications. 
Dieckmann, A. and J. Rieskamp (2007), 'The influence of information redundancy on probabilistic inferences', Memory \& Cognition, 35(7): 1801-1813.

Elmendorf, C. S. and A. K. Wood (2018), 'Elite political ignorance: Law, data, and the representation of (mis) perceived electorates', UC Davis Law Review, 52: 571-636.

Fenno, R. F. (1978), Home style: House members in their districts. Boston: Little, Brown.

Fuller, T. (2020), California Governor declares homeless crisis 'a disgrace'. The New York Times. Retrieved from: https:/www.nytimes.com/2020/02/19/us/california-homeless.html.

Garcia-Retamero, R. and M. K. Dhami (2009), 'Take-the-best in expert-novice decision strategies for residential burglary', Psychonomic Bulletin \& Review, 16(1): 163-169.

Gigerenzer, G. (2008), Rationality for mortals: How people cope with uncertainty, New York: Oxford University Press.

Gigerenzer, G. and W. Gaissmaier (2011), 'Heuristic decision making', Annual Review of Psychology, 62: 451-482.

Gigerenzer, G., P. M. Todd and ABC Research Group T. (1999), Simple heuristics that make us smart, New York: Oxford University Press.

Gosling, S. D., S. J. Ko, T. Mannarelli and M. E. Morris (2002), 'A room with a cue: Personality judgments based on offices and bedrooms', Journal of Personality and Social Psychology, 82(3): 379.

Hogarth, R. M. and N. Karelaia (2007), 'Heuristic and linear models of judgment: Matching rules and environments', Psychological Review, 114(3): 733.

Jennings, W. and C. Wlezien (2011), 'Distinguishing between most important problems and issues?', Public Opinion Quarterly, 75(3): 545-555.

Jones, B. D. and F. R. Baumgartner (2004), 'Representation and agenda setting', Policy Studies Journal, 32(1): 1-24.

Jones, B. D. and F. R. Baumgartner (2005), The politics of attention: How government prioritizes problems, Chicago: University of Chicago Press.

Kahneman, D., S. P. Slovic, and A. Tversky (Eds.) (1982), Judgment under uncertainty: Heuristics and biases, New York: Cambridge University Press.

Kalla, J. L., and E. Porter (2019), 'Correcting bias in perceptions of public opinion among American elected officials: Results from two field experiments', British Journal of Political Science, 1-9.

Kingdon, J. W. (1984), Agendas, alternatives, and public policies, Boston: Little Brown.

Krosnick, J. A., S. Narayan and W. R. Smith (1996), 'Satisficing in surveys: Initial evidence', New Directions for Evaluation, 1996(70): 29-44.

Kunda, Z. (1990), 'The case for motivated reasoning', Psychological Bulletin, 108(3): 480-498.

Landy, D., B. Guay, and T. Marghetis (2018), 'Bias and ignorance in demographic perception', Psychonomic Bulletin and Review, 25(5): 1606-1618.

Leeper, T. J., and R. Slothuus (2014), 'Political parties, motivated reasoning, and public opinion formation', Political Psychology, 35: 129-156.

Lowry, D. T., T. C. J. Nio and D. W. Leitner (2003), 'Setting the public fear agenda: A longitudinal analysis of network TV crime reporting, public perceptions of crime, and FBI crime statistics', Journal of Communication, 53(1): 61-73.

Mansbridge, J. (2003), 'Rethinking representation', American Political Science Review, 97(4): $515-528$.

Manza, J., and F. L. Cook (2002), 'A democratic polity? Three views of policy responsiveness to public opinion in the United States', American Politics Research, 30(6): 630-667.

Michigan 2-1-1 2017, Michigan 2-1-1 call data (2017) [Data set]. Michigan Association of United Ways. Retrieved from: https://www.uwmich.org/mi211.

Miler, K. C. (2007), 'The view from the hill: Legislative perceptions of the district', Legislative Studies Quarterly, 32(4): 597-628.

Pitkin, H. F. (1967), The concept of representation, Berkeley: University of California Press. 
Poole, K. T., and H. Rosenthal (1997), Congress: A Political-Economic History of Roll Call Voting, New York: Oxford University Press.

Rehfeld, A. (2009), 'Representation rethought: On trustees, delegates, and gyroscopes in the study of political representation and democracy', American Political Science Review, 103(2): 214-230.

Rose, M. and F. R. Baumgartner (2013), 'Framing the poor: Media coverage and US poverty policy, 1960-2008', Policy Studies Journal, 41: 22-53.

Schmälzle, R., F. M. Hartung, A. Barth, M. A. Imhof, A. Kenter, B. Renner and H. T. Schupp (2019), 'Visual cues that predict intuitive risk perception in the case of HIV', PLOS ONE, 14(2): 1-17.

Schneider, A., and H. Ingram (1993), 'Social construction of target populations: Implications for politics and policy', American Political Science Review, 87(2): 334-347.

Shapiro, R. Y. (2011), 'Public opinion and American democracy', Public Opinion Quarterly, 75(5): 982-1017.

Sheffer, L. (2018). Behavioural foundations of elite politics: How individual-level characteristics shape the decision making of elected politicians [Unpublished doctoral dissertation], University of Toronto.

Shulman, H. C. and F. J. Boster (2014), 'The effect of test-taking venue and test format on political knowledge test performance', Communication Methods and Measures, 8: 177-189.

Simon, H. A. (1957), Models of man: social and rational; mathematical essays on rational human behavior in society setting, New York: Wiley.

Simon, H. A. (1990), 'Invariants of human behavior', Annual Review of Psychology, 41: 1-19.

Tversky, A., and D. Kahneman (1973), 'Availability: A heuristic for judging frequency and probability', Cognitive Psychology, 5(2): 207-232.

Van der Pas, D. J., W. Van der Brug and R. Vliegenthart (2017), 'Political parallelism in media and political agenda-setting', Political Communication, 34(4): 491-510.

Walker, J. L. (1969), 'The diffusion of innovations among the American states', American Political Science Review, 63(3): 880-899.

Wolfe, M., B. D. Jones and F. R. Baumgartner (2013), 'A failure to communicate: Agenda setting in media and policy studies', Political Communication, 30(2): 175-192.

Wong, C. J. (2007), “'Little" and "big” pictures in our heads: Race, local context, and innumeracy about racial groups in the United States', Public Opinion Quarterly, 71(3): 392-412.

Wlezien, C. (2005), 'On the salience of political issues: The problem with 'most important problem", Electoral Studies, 24(4): 555-579.

Wright, J. R. (1996), Interest groups and Congress: Lobbying, contributions, and influence. Boston: Allyn and Bacon.

Zahariadis, N. (2003), Ambiguity and choice in public policy: Political decision making in modern democracies, Washington, D.C.: Georgetown University Press.

Zahariadis, N. (2008). 'Ambiguity and choice in European public policy', Journal of European Public Policy, 15(4): 514-530.

Zahariadis, N. (2013), 'Building better theoretical frameworks of the European Union's policy process', Journal of European Public Policy, 20(6): 807-816. 


\section{Appendix}

Table A1. Ordered logit estimates of policymaker perceptions of citizen needs.

\begin{tabular}{|c|c|c|c|c|c|c|c|c|c|}
\hline \multicolumn{10}{|c|}{ Ordered logit estimates } \\
\hline & Poverty & Food & Health care & Child care & $\begin{array}{l}\text { Emergency } \\
\text { housing }\end{array}$ & Transportation & Job training & $\begin{array}{l}\text { Drug } \\
\text { treatment }\end{array}$ & $\begin{array}{l}\text { Affordable } \\
\text { housing }\end{array}$ \\
\hline $\begin{array}{l}\text { Poverty rate } \\
\text { (5-year ACS) }\end{array}$ & $0.13 *(0.02)$ & - & - & - & - & - & - & - & - \\
\hline $\ln (1+$ calls $)$ & - & $0.45 *(0.15)$ & $0.60 *(0.18)$ & $0.28(0.19)$ & $0.47^{*}(0.16)$ & $0.04(0.13)$ & $0.09(0.22)$ & $0.19(0.23)$ & $0.00(0.16)$ \\
\hline $\ln$ (population) & $-0.06(0.12)$ & $-0.27(0.20)$ & $-0.66 *(0.20)$ & $-0.23(0.22)$ & $-0.56^{*}(0.20)$ & $0.00(0.13)$ & $-0.35(0.20)$ & $-0.42 *(0.18)$ & $-0.10(0.19)$ \\
\hline Republican & $0.14(0.39)$ & $-0.73(0.37)$ & $-0.78(0.42)$ & $-1.1 *(0.42)$ & $-0.08(0.33)$ & $-0.02(0.32)$ & $-0.54(0.36)$ & $-0.28(0.44)$ & $-0.44(0.31)$ \\
\hline Democrat & $-0.16(0.37)$ & $-0.52(0.41)$ & $0.61(0.43)$ & $-0.19(0.43)$ & $0.19(0.35)$ & $0.41(0.36)$ & $0.18(0.37)$ & $0.12(0.49)$ & $0.15(0.33)$ \\
\hline$\kappa_{1}$ & $-0.16(1.2)$ & $-4.0(1.5)$ & $-7.8(1.6)$ & $-5.0(1.6)$ & $-4.7(1.4)$ & $-2.7(1.1)$ & $-6.3(1.7)$ & $-6.6(1.4)$ & $-3.8(1.3)$ \\
\hline$\kappa_{2}$ & $1.4(1.2)$ & $-.31(1.5)$ & $-4.5(1.5)$ & $-2.0(1.5)$ & $-2.8(1.4)$ & $0.27(1.1)$ & $-3.6(1.6)$ & $-4.4(1.3)$ & $-1.4(1.2)$ \\
\hline$\kappa_{3}$ & $2.6(1.2)$ & $2.3(1.6)$ & $-2.2(1.5)$ & $0.06(1.5)$ & $-0.78(1.4)$ & $1.7(1.1)$ & $-1.9(1.6)$ & $-2.4(1.3)$ & $0.30(1.2)$ \\
\hline$\kappa_{4}$ & $3.5(1.3)$ & - & - & - & - & - & - & - & - \\
\hline$\kappa_{5}$ & $5.4(1.3)$ & - & - & - & - & - & - & - & - \\
\hline$N$ & 186 & 189 & 154 & 150 & 179 & 193 & 170 & 157 & 194 \\
\hline Pseudo- $R^{2}$ & 0.12 & 0.05 & 0.07 & 0.04 & 0.03 & 0.00 & 0.02 & 0.02 & 0.01 \\
\hline
\end{tabular}

" $\mathrm{p}<0.05$, two-tailed. Robust standard errors clustered by city in parentheses. 
Table A2. Estimates of interaction terms in predicting policymaker perceptions of citizen needs.

\begin{tabular}{|c|c|c|c|c|c|c|c|c|c|}
\hline & Poverty & Food & Health care & Child care & $\begin{array}{l}\text { Emergency } \\
\text { housing }\end{array}$ & Transportation & Job training & $\begin{array}{l}\text { Drug } \\
\text { treatment }\end{array}$ & $\begin{array}{l}\text { Affordable } \\
\text { housing }\end{array}$ \\
\hline $\begin{array}{l}\ln (1+\text { calls }) \times \\
\text { quality }\end{array}$ & $0.01(0.01)$ & $0.03(0.03)$ & $0.08(0.05)$ & $-.02(0.05)$ & $-0.07(0.05)$ & $0.05(0.07)$ & $0.01(0.06)$ & $0.04(0.07)$ & $-0.06(0.06)$ \\
\hline$N$ & 185 & 187 & 153 & 150 & 178 & 191 & 169 & 156 & 192 \\
\hline$R^{2}$ & 0.34 & 0.09 & 0.16 & 0.08 & 0.11 & 0.05 & 0.04 & 0.06 & 0.03 \\
\hline $\begin{array}{c}\ln (1+\text { calls }) \times \ln \\
\text { (population) }\end{array}$ & $0.00(0.01)$ & $0.01(0.02)$ & $-0.03(0.02)$ & $-0.03(0.03)$ & $0.04(0.03)$ & $0.02(0.03)$ & $0.02(0.05)$ & $0.08 *(0.04)$ & $0.05(0.03)$ \\
\hline$N$ & 186 & 189 & 154 & 150 & 179 & 193 & 170 & 157 & 194 \\
\hline$R^{2}$ & 0.34 & 0.07 & 0.15 & 0.09 & 0.07 & 0.01 & 0.04 & 0.07 & 0.04 \\
\hline $\begin{array}{l}\ln (1+\text { calls }) \times \% \\
\text { minority }\end{array}$ & $-0.06(0.05)$ & $0.16(0.18)$ & $0.16(0.27)$ & $0.48(0.28)$ & $0.18(0.38)$ & $-0.03(0.27)$ & $0.20(0.50)$ & $0.77^{*}(0.39)$ & $0.04(0.32)$ \\
\hline$N$ & 186 & 189 & 154 & 150 & 170 & 193 & 170 & 157 & 194 \\
\hline$R^{2}$ & 0.35 & 0.09 & 0.15 & 0.11 & 0.06 & 0.03 & 0.04 & 0.06 & 0.04 \\
\hline $\begin{array}{l}\ln (1+\text { calls }) \times \\
\text { Republican }\end{array}$ & $0.01(0.02)$ & $0.05(0.06)$ & $0.25 *(0.09)$ & $0.07(0.13)$ & $-0.15(0.11)$ & $-0.08(0.10)$ & $-0.11(0.15)$ & $0.17(0.16)$ & $-0.07(0.12)$ \\
\hline $\begin{array}{c}\ln (1+\text { calls }) \times \\
\text { Democrat }\end{array}$ & $-0.02(0.02)$ & $0.04(0.07)$ & $0.18(0.10)$ & $0.07(0.13)$ & $-0.07(0.10)$ & $0.10(0.13)$ & $0.05(0.16)$ & $0.26(0.18)$ & $-0.12(0.11)$ \\
\hline$N$ & 186 & 189 & 154 & 150 & 179 & 193 & 170 & 157 & 194 \\
\hline$R^{2}$ & 0.35 & 0.08 & 0.17 & 0.09 & 0.07 & 0.03 & 0.05 & 0.06 & 0.03 \\
\hline
\end{tabular}

* $\mathrm{p}<0.05$, two-tailed. Robust standard errors clustered by city in parentheses. Models include controls for $\ln ($ population), $\ln (1+$ number of calls), indicators for Democratic and Republican party, as well as communication quality (row 1) and percent minority (row 2) (control coefficients not displayed). 